\title{
Integrated Woodencraft Cluster : Program Akselerasi Usaha Kecil dan Menengah (UKM) Go International sebagai Upaya Pemberdayaan UKM Potensial Yogyakarta
}

\author{
Ismianti $^{1}$, Yun Prihantina Mulyani ${ }^{2}$, Rasyid Halimi ${ }^{3}$, Oktiyanto Ade Saputro ${ }^{4}$ \\ ${ }^{1}$ Jurusan Teknik Industri \\ Universitas Pembangunan Nasional Veteran Yogyakarta, Jl. Babarsari 2, Tambakbayan, Yogyakarta 55281 \\ 2 Departemen Teknik Mesin dan Industri \\ Universitas Gadjah Mada, Jl. Grafika No. 2 Yogyakarta 55284 \\ email : ismianti@upnyk.ac.id \\ doi: https://doi.org/10.31315/opsi.v12i2.3119
}

Received: $19^{\text {th }}$ November 2019; Revised: $30^{\text {th }}$ December 2019; Accepted: $30^{\text {th }}$ December 2019; Available online : $31^{\text {th }}$ December 2019; Published regularly : December 2019

\begin{abstract}
Small and Medium Enterprises (SMEs) have a very important role in the development of the Indonesian economy. Special Region of Yogyakarta (DIY) is one of the provinces that has many SMEs. The SMEs has the potential to penetrate the international market, one of which is a wooden handicraft SMEs. Woodencraft can be used as a cluster because it fulfills three factors that enable it to compete in the international market, namely the factor of global market needs, the factor of superior products, and potential SME product factors. However, woodencraft SMEs still face obstacles in product penetration abroad, namely obstacles from internal SMEs, the government, and international markets. The solution offered to help woodencraft SMEs to go international a program called Integrated Woodencraft Cluster, which is a cluster of woodencraft SMEs that integrates supply chain management (SCM) based distribution systems with four main lines (suppliers, production, sales, and information), internetbased information systems, and Just In Time (JIT) principle. The program involves local government, civil service, wood handicraft SMEs, suppliers of raw materials, and academics. The advantages of Integrated Woodencraft Clusters compared to conventional clusters include having a clear vision for exporting production, a structured managerial system, having an export agency, supplying raw materials, clear lines of information, and being able to facilitate all SME woodencraft, both on a small scale and intermediate.
\end{abstract}

Keywords: cluster; go international; SMEs; woodencraft

\begin{abstract}
ABSTRAK
Usaha Kecil dan Menengah (UKM) mempunyai peranan yang sangat penting dalam pembangunan perekonomian Indonesia. Daerah Istimewa Yogyakarta (DIY) termasuk salah satu provinsi yang mempunyai banyak UKM. UKM tersebut berpotensi untuk menembus pasar internasional, salah satunya adalah UKM kerajinan kayu. Kerajinan kayu dapat dijadikan klaster karena memenuhi tiga faktor yang memungkinkan untuk bersaing di pasar internasional, yaitu faktor kebutuhan pasar global, faktor produk unggulan, dan faktor produk UKM potensial. Namun, UKM kerajinan kayu masih menghadapi kendala dalam penetrasi produk ke luar negeri, yaitu kendala dari internal UKM, pemerintah, dan pasar internasional. Solusi yang ditawarkan untuk membantu UKM kerajinan kayu agar dapat go international berupa sebuah program bernama Integrated Woodencraft Cluster, yaitu sebuah klaster UKM kerajinan kayu yang mengintegrasikan aplikasi sistem distribusi berbasis Supply Chain Management (SCM) dengan empat lini utama (supplier, produksi, penjualan, dan informasi), sistem informasi berbasis internet, dan prinsip Just In Time (JIT). Program tersebut melibatkan pemerintah daerah, pamong praja, pelaku UKM kerajinan kayu, pemasok bahan baku, dan akademisi. Keunggulan Integrated Woodencraft Cluster jika dibandingkan dengan klaster konvensional antara lain mempunyai visi yang jelas untuk mengekspor hasil produksi, sistem manajerial yang terstruktur, memiliki badan ekspor, pemasok bahan baku, lini informasi yang jelas, serta dapat memfasilitasi semua UKM kerajinan kayu, baik yang berskala kecil maupun menengah.
\end{abstract}

Kata Kunci: Kerajinan Kayu; Klaster; UKM; pasar global 


\section{PENDAHULUAN}

Usaha Kecil dan Menengah (UKM) merupakan merupakan sektor yang sangat penting dalam membangun perekonomian Indonesia, terutama dalam masa-masa kritis. Pengalaman masa lalu menunjukkan bahwa sektor riil yang dikuasai oleh perusahaan konglomerasi yang tidak didukung oleh kinerja yang baik, menyebabkan mereka menjadi bangkrut akibat krisis, yang selanjutnya dalam skala yang lebih luas menjadikan negara Indonesia terpuruk karena jumlah mereka yang sedikit ternyata menguasai sebagian besar perekonomian nasional. Di sisi lain, UKM yang jumlahnya sangat banyak namun mempunyai porsi peranan yang kecil dalam perekonomian nasional, ternyata mampu bertahan dalam situasi krisis. Hal ini menunjukkan bahwa ketahanan perekonomian nasional Indonesia sesungguhnya berada pada UKM yang secara masal merupakan skala ekonomi kerakyatan (Aziz, 2007). UKM termasuk industri yang mampu memberikan kontribusi untuk meningkatkan persaingan pasar serta stabilitas pada system ekonomi yang ada (Sari dan Yasa, 2016).

Selain itu, sektor UKM juga mempunyai peranan yang sangat penting dalam penyerapan tenaga kerja. Pada saat banyak pekerja yang terkena Pemutusan Hubungan Kerja (PHK) akibat krisis global, UKM dapat menjadi solusi yang paling baik untuk menghindari pengangguran (Zen, 2009). Berdasarkan data yang dipublikasikan oleh Kementerian Negara Koperasi dan UKM menunjukkan bahwa tenaga kerja yang bekerja pada sektor UKM mencapai 96 persen (2000-2006) terhadap total tenaga kerja yang tersebar di sembilan sektor ekonomi Indonesia (Wahyudi, 2009).

Dari berbagai daerah di Indonesia, salah satu daerah yang memiliki jumlah UKM cukup banyak adalah di Daerah Istimewa Yogyakarta (DIY). Selain itu, UKM di DIY ini menarik untuk dikaji karena naik turunnya jumlah UKM sangat fluktuatif mengingat banyak bencana yang melanda. Sebagai contoh pada tahun 1998, DIY termasuk provinsi yang mengalami kemerosotan ekonomi terparah (Mukaffi, 2010). Namun pada tahun 2009, jumlah UKM di DIY sudah mencapai 12913 unit dengan nilai produksi sebesar Rp 198.258.537.000,00 (Disperindagkop DIY, 2009). Peningkatan nilai produksi tersebut menjadi indikator potensi perkembangan UKM DIY. Potensi tersebut seharusnya dimanfaatkan sebagai langkah ekspansi Indonesia dalam bidang ekspor. Namun, dari banyak UKM di DIY ini, baru segelintir UKM yang dapat menembus pasar internasional. Dengan berbagai alasan mulai dari kualitas produk, birokrasi, sampai ketatnya persaingan internasional membuat UKM enggan untuk mengejar pasar ekspor. Memang berbagai kendala tersebut menjadi penghalang untuk dapat menembus pasar global. Akan tetapi, mengejar pasar ekspor juga sangat penting karena daya serap tenaga UKM jauh lebih besar daripada industri besar dan secara otomatis mengurangi angka pengangguran serta meningkatkan pendapatan maupun untuk kepentingan citra negara.

Salah satu UKM DIY yang sudah masuk dalam pasar ekspor adalah UKM kerajinan kayu. Produk ini menjadi produk unggulan pasar domestik (Winarto dan Nazir, 2006), hanya saja sampai saat ini penetrasi produk kerajinan kayu ke pasar luar negeri belum terkoordinasi sehingga hasilnya belum maksimal. UKM kerajinan kayu yang dapat ekspor pun hanya melingkupi UKM skala menengah ke atas. Melihat kenyataan tersebut, maka dibutuhkan strategi untuk membantu UKM-UKM kerajinan kayu di DIY skala kecil agar dapat go international bersama dengan UKM skala menengah atau besar. Strategi yang diusulkan adalah Integrated Woodencraft Cluster yang merupakan sebuah klaster UKM kerajinan kayu dengan mengintegrasikan aplikasi sistem distribusi berbasis Supply Chain Management (SCM), sistem informasi berbasis website, dan prinsip Just In Time (JIT). UKM yang berbasis kluster lebih berpotensi dalam peningkatan produktivitas dan menembus pasar global (Foghani, 2017).

\section{METODE}

\subsection{Studi Literatur}

Indonesia memiliki banyak UKM dengan spesifikasi hasil produk yang berbeda. Namun sayangnya, UKM tersebut hanya memenuhi kebutuhan domestik saja. Sangat sedikit UKM yang dapat menembus pasar global. Hal tersebut dikarenakan tidak semua UKM berpotensi untuk dikembangakan. Jenis UKM potensial tergantung dari tiga faktor faktor utama, yaitu ketersediaan modal, bahan baku, dan tenaga kerja (Marijan, 2005). Ketersediaan bahan baku dan tenaga kerja, dan didukung dengan modal 
yang besar memungkinkan UKM untuk memproduksi dalam jumlah yang lebih besar.

Analisis UKM potensial belum cukup sebagai dasar pengembangan go international. Persaingan dalam perdagangan internasional sangat ditentukan oleh tiga hal yaitu Kualitas produk unggulan, Kuantitas/ Kapasitas UKM, dan Demand/ kebutuhan luar negri

Kualitas erat kaitannya dengan produk yang dapat bersaing dengan produk-produk lain di pasar terbuka. Kualitas menjadi salah satu motif pemilihan produk oleh konsumen.

Kemampuan produksi dilihat dari 3 faktor yang telah disebutkan di atas yaitu modal, bahan baku, dan tenaga kerja. Hal ini menjadi modal utama UKM berpotensi atau berkemampuan memproduksi dalam kuantitas yang besar.

Walaupun poin 1 dan 2 dapat dipenuhi oleh sebuah UKM, belum cukup menyatakan bahwa UKM tersebut bepotensi go internasional. Poin ketiga adalah kebutuhan atau demand luar negeri. Ketika produk secara kuantitatif dan kualitatif tersedia, tetapi pihak konsumen tidak membutuhkan, produk pun tidak dapat masuk pada negara tersebut.

Ketiga faktor di atas dapat dianalisis dengan beberapa parameter yang berasal dari data-data kuantitatif dan kualitatif, yaitu berdasarkan kebutuhan pasar global, produk unggulan, dan produk UKM potensial.

\subsubsection{Kebutuhan pasar global}

Kebutuhan pasar internasional terhadap suatu produk sangat berpengaruh terhadap permintaan produk tersebut. Kebutuhan pasar internasional dapat dilihat dari jumlah produk yang diekspor ke luar negeri. Tabel 1 adalah adalah data perkembangan komoditi utama ekspor DIY tahun 2007-2010 (Disperindagkom DIY, 2011). Dari 20 komoditi yang diekspor didapatkan demand yang terus meningkat atau stabil dari tahun 2007 ke 2010 untuk produkproduk ekspor di DIY antara lain tekstil, sarung tangan dan kaos kaki (STK) sintesis, minyak kenanga, arang briket, teh hijau/hitam, dan kerajinan kayu. Dari beberapa komoditi tersebut tidak semua komoditi dihasilkan dari UKM. Hal ini dapat dilihat dari data UKM yang ada di Yogyakarta tahun 2008-2009. Misalnya arang briket, kenanga, teh hijau/hitam, dan STK sintesis produk-produk tersebut hanya dihasilkan oleh industri skala menengah. Produk yang dihasilkan oleh UKM hanya tekstil dan kerajinan kayu.

Tabel 1. Perkembangan Komoditi Utama Ekspor DIY Tahun 2007-2010

\begin{tabular}{|c|c|c|c|c|c|}
\hline \multirow[t]{2}{*}{ No. } & \multirow[t]{2}{*}{ Komoditi } & \multicolumn{4}{|c|}{ Nilai Penjualan (juta US \$) } \\
\hline & & 2007 & 2008 & 2009 & 2010 \\
\hline 1 & $\begin{array}{l}\text { Pakaian jadi } \\
\text { tekstil }\end{array}$ & 34,41 & 33,9 & 27,7 & 39,16 \\
\hline 2 & Mebel kayu & 26,1 & 24,28 & 18,67 & 16,93 \\
\hline 3 & $\begin{array}{l}\text { Sarung tangan } \\
\text { kulit }\end{array}$ & 10,56 & 16,93 & 11,35 & 15,17 \\
\hline 4 & STK sintetis & 6,69 & 6,94 & 9,18 & 13,3 \\
\hline 5 & $\begin{array}{l}\text { Kerajinan } \\
\text { kayu }\end{array}$ & 4,85 & 5,14 & 4,96 & 3,92 \\
\hline 6 & $\begin{array}{l}\text { Kerajinan } \\
\text { batu }\end{array}$ & 3,14 & 3,47 & 3,74 & 3,71 \\
\hline 7 & $\begin{array}{l}\text { STK } \\
\text { Polyurethan }\end{array}$ & 0,63 & 2,7 & 3,47 & 1,64 \\
\hline 8 & Kulit disamak & 7,12 & 6,69 & 3,34 & 2,77 \\
\hline 9 & $\begin{array}{l}\text { kerajinan } \\
\text { kertas }\end{array}$ & 4,55 & 4,2 & 2,9 & 5,61 \\
\hline 10 & $\begin{array}{l}\text { Teh } \\
\text { hijau/hitam }\end{array}$ & 1,05 & 1,75 & 2,85 & 3,63 \\
\hline 11 & $\begin{array}{l}\text { Atsiri daun } \\
\text { cengkeh }\end{array}$ & 4,71 & 3,08 & 2,63 & 1,83 \\
\hline 12 & Arang briket & 1,16 & 0,96 & 1,9 & 2,06 \\
\hline 13 & $\begin{array}{l}\text { Minyak } \\
\text { kenanga }\end{array}$ & 0,12 & 0,3 & 1,73 & 3,09 \\
\hline 14 & $\begin{array}{l}\text { Kerajinan } \\
\text { perak }\end{array}$ & 1,3 & 1,38 & 1,58 & 1,33 \\
\hline 15 & Mesin & 0 & 0 & 1,43 & 0,42 \\
\hline 16 & Lampu & 2,99 & 1,51 & 1,29 & 0,83 \\
\hline 17 & $\begin{array}{l}\text { Kerajinan } \\
\text { kulit }\end{array}$ & 1,8 & 1,26 & 1,02 & 1,27 \\
\hline 18 & $\begin{array}{l}\text { Produk tekstil } \\
\text { lain }\end{array}$ & 0,32 & 0,71 & 0,86 & 3,17 \\
\hline 19 & $\begin{array}{l}\text { Kerajinan } \\
\text { tanah liat }\end{array}$ & 1,82 & 0,99 & 0,85 & 0,62 \\
\hline 20 & $\begin{array}{l}\text { Arang } \\
\text { burcette }\end{array}$ & 0 & 2,64 & 0,85 & 0 \\
\hline
\end{tabular}

\subsubsection{Produk unggulan}

Berdasarkan penelitian yang dilakukan oleh Winarto dan Nazir (2006), setiap daerah memiliki produk unggulan yang berbeda-beda. Produk unggulan ini dilihat dari sisi daya dukung sumber bahan baku lokal sehingga cukup modal untuk memperolehnya dan sebagian besar dari produk unggulan sudah berorientasi untuk pasar ekspor. Data lengkap produk unggulan beberapa wilayah di Indonesia dapat dilihat pada Tabel 2. Dari kedua sisi tersebut didapatkan produk unggulan untuk wilayah DIY adalah kerajinan bambu, serat alam, dan kerajinan kayu. 
Tabel 2. Daftar Produk Unggulan di Indonesia Menurut Provinsi

\begin{tabular}{|c|c|c|c|}
\hline No & Provinsi & $\begin{array}{c}\text { Kota/ Kab. } \\
\text { Sampel }\end{array}$ & $\begin{array}{c}\text { Produk } \\
\text { Unggulan }\end{array}$ \\
\hline 1 & $\begin{array}{l}\text { Jawa } \\
\text { Timur }\end{array}$ & $\begin{array}{l}\text { Kota Batu } \\
\text { Kabupaten } \\
\text { Sidoarjo }\end{array}$ & $\begin{array}{l}\text { keripik apel, sari } \\
\text { apel, jus apel } \\
\text { bordir, sepatu, } \\
\text { batik tulis }\end{array}$ \\
\hline 2 & $\begin{array}{l}\text { D.I. } \\
\text { Yogyakarta }\end{array}$ & $\begin{array}{l}\text { Kabupaten } \\
\text { Sleman } \\
\text { Kabupaten } \\
\text { Bantul }\end{array}$ & $\begin{array}{l}\text { kerajinan bambu } \\
\text { tenun serat } \\
\text { alam, kerajinan } \\
\text { kayu }\end{array}$ \\
\hline 3 & $\begin{array}{l}\text { Nusa } \\
\text { Tenggara } \\
\text { Barat }\end{array}$ & $\begin{array}{l}\text { Kota } \\
\text { Mataram } \\
\text { Kabupaten } \\
\text { Lombok } \\
\text { Barat }\end{array}$ & $\begin{array}{l}\text { kerajinan } \\
\text { anyaman } \\
\text { gerabah/keramik }\end{array}$ \\
\hline 4 & $\begin{array}{l}\text { Sulawesi } \\
\text { Tenggara }\end{array}$ & $\begin{array}{l}\text { Kota Abu- } \\
\text { abu dan } \\
\text { Kabupaten } \\
\text { Buton }\end{array}$ & $\begin{array}{l}\text { Coklat } \\
\text { kacang mete, } \\
\text { udang, ikan } \\
\text { kerapu, kopra }\end{array}$ \\
\hline 5 & $\begin{array}{l}\text { Sumatera } \\
\text { Utara }\end{array}$ & $\begin{array}{l}\text { Kota Medan } \\
\text { dan } \\
\text { Kabupaten } \\
\text { Langkap }\end{array}$ & $\begin{array}{l}\text { anyaman rotan, } \\
\text { sepatu }\end{array}$ \\
\hline
\end{tabular}

\subsubsection{Produk produk UKM potensial}

Produk dari UKM potensial dapat dilihat dari segi modal, tenaga kerja, dan bahan baku. Berdasarkan ketiga faktor tersebut, jenis-jenis UKM yang berpotensi di wilayah DIY antara lain: kerajinan kayu, kerajinan bambu, gerabah, tekstil, dan serat alam (Disperindagkom, 2011).

\subsection{Metode Pengumpulan Data}

Metode yang digunakan dalam identifikasi UKM potensial go international ini adalah kajian literatur, wawancara, dan diskusi. Wawancara dan diskusi dilakukan dengan Dinas Perindustrian dan Perdagangan Daerah Istimewa Yogyakarta dan pelaku UKM kerajinan kayu.

\section{HASIL DAN PEMBAHASAN}

Berdasarkan tiga parameter seleksi go internasional didapatkan gambar seleksi yang ditunjukkan dalam diagram Venn pada Gambar 1.

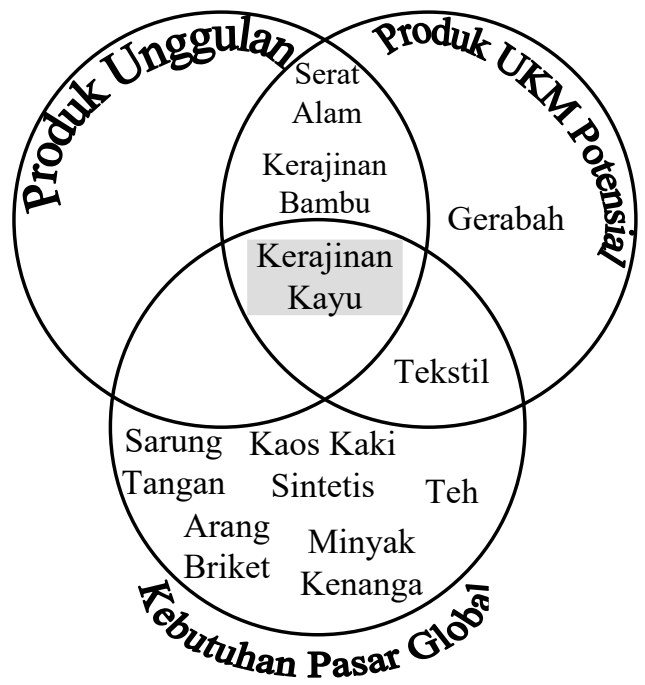

Gambar 1. Diagram Seleksi UKM Berpotensi Go International

Dari ketiga parameter tersebut didapatkan produk yang potensial untuk go Internasional untuk UKM-UKM di DIY adalah kerajinan kayu. Kerajinan kayu ini sangat potensial untuk go Internasional karena pertumbuhan demand ke depan cenderung meningkat, bahan baku melimpah dan mudah didapatkan (produk unggulan), dan UKM nya potensial berdasar tenaga kerja, modal, bahan baku dan demand pasar.

UKM kerajinan kayu di wilayah DIY mempunyai potensi untuk dikembangkan menjadi UKM yang berorientasi gointernational. Meskipun demikian, terdapat beberapa kendala yang menghambat proses pengembangannya, seperti yang dapat dilihat pada Gambar 2 (Global Facilitation Partnership, 2005). Sebagai solusi dari kesulitan UKM kerajinan kayu di Yogyakarta untuk menembus pasar global, ditawarkan sebuah konsep klaster UKM dengan mengintegrasikan antara para penggerak klaster dengan sistem distribusi berbasis Supply Chain Management (SCM), sistem informasi berbasis website, dan prinsip Just In Time (JIT), yang kemudian disebut dengan Integrated Woodencraft Cluster atau Klaster Kerajinan Kayu Terintegrasi. Gambar 3 merupakan gambaran dari Integrated Woodencraft Cluster. 


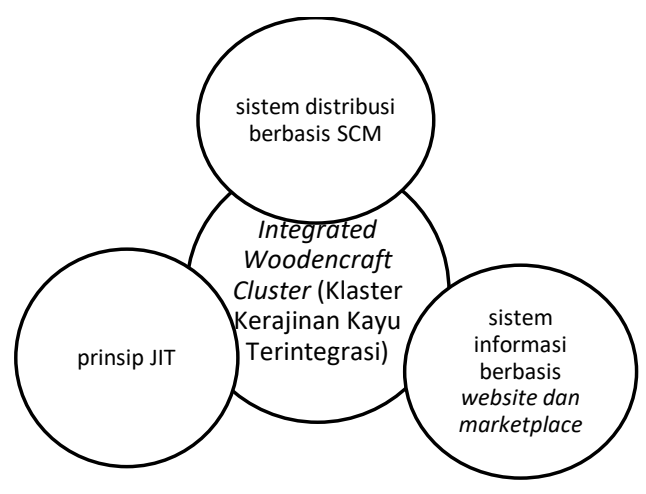

Gambar 3. Gambaran Intregated Woodencraft Cluster

Integrated Woodencraft Cluster ini bertujuan untuk mewadahi para pelaku UKM kerajinan kayu yang berasal dari berbagai sentra UKM kerajinan kayu di Yogyakarta, sehingga produk kerajinan kayu tersebut dapat dikelola dengan baik, mulai dari pencarian bahan baku, produksi, distribusi, sampai promosi dan penjualan, baik untuk pasar dalam negeri maupun pasar luar negeri.

Integrated Woodencraft Cluster secara umum terdiri dari para pelaku UKM, pemasok bahan baku, bagian penjualan, serta bagian informasi. Keenam bagian tersebut saling berkoordinasi satu sama lain dan menjadi bagian seutuhnya dari klaster serta bersifat independent dengan pihak luar.

Secara garis besar, Integrated Woodencraft Cluster tidak begitu berbeda dengan klaster UKM lain pada umumnya. Klaster tersebut sama-sama menjadi pusat dari kelompok industri sejenis yang hanya berlokasi pada suatu wilayah tertentu. Namun, jika dilihat dari interaksi internalnya, Integrated Woodencraft Cluster mempunyai sistem yang lebih kompleks, dengan melibatkan semua aspek produksi dari pemasok bahan baku sampai bagian penjualan, dari bagian distribusi sampai bagian informasi. Hal inilah yang mendasari perbedaan antara Integrated Woodencraft Cluster dengan sistem klaster konvensional, yang secara umum hanya melibatkan bagian produksi sampai bagian penjualan.

Kendala-kendala tersebut secara umum dibagi menjadi tiga, yaitu dari sisi UKM, pemerintah, dan pasar internasional. Karena kendala yang berasal dari pihak pemerintah dan pasar internasional sulit untuk dihilangkan, maka kendala dari sisi UKM lah yang harus dihilangkan dengan memberikan solusi-solusi aplikatif agar dapat diterapkan pada UKM sehingga internasionalisasi UKM kerajinan kayu dapat segera tercapai.

\subsection{Subjek Terkait}

Pengembangkan Integrated Woodencraft Cluster diperlukan kerja sama antara beberapa pihak yang terkait secara langsung, yaitu antara Pemerintah DIY, pamong praja, pelaku UKM, pemasok bahan baku, dan mahasiswa. Kerja sama tersebut dilakukan sesuai dengan porsi dan perannya masing-masing.

\subsubsection{Pemerintah DIY}

Pemerintah DIY sangat berperan dalam pembentukan Integrated Woodencraft Cluster. Peran yang sangat nyata adalah dalam hal pemberian ijin pembentukan klaster kerajinan kayu di DIY serta dalam hal bantuan pendanaan untuk pembentukan dan pengembangannya.

\subsubsection{Pamong Praja}

Pamong praja yang dimaksud dalam konteks ini adalah para pejabat pemerintahan mulai tingkat dusun hingga tingkat kecamatan. Mereka yang akan diberi wewenang oleh Pemerintah DIY untuk membentuk dan menyusun organisasi kepengurusan di dalam klaster.

\subsubsection{Pelaku UKM Kerajinan Kayu}

Para pelaku UKM kerajinan kayu mempunyai peran yang paling penting karena posisi mereka sebagai penggerak primer di dalam klaster. Para pelaku UKM inilah yang akan memproduksi barang-barang kerajinan yang berasal dari kayu yang akan menjadi komoditi unggulan dan satu-satunya di dalam Integrated Woodencraft Cluster.

\subsubsection{Pemasok Bahan Baku}

Pemasok bahan baku berperan dalam menyediakan bahan baku yang akan diolah menjadi barang jadi berupa kerajinan kayu. Tanpa para pemasok, Integrated Woodencraft Cluster tidak dapat menjalankan fungsinya.

\subsubsection{Akademisi}

Akademisi juga mempunyai peranan dalam pembentukan Integrated Woodencraft Cluster. Peran akademisi dalam hal ini adalah dengan menyelenggarakan pelatihan bagi para pengurus klaster. Pelatihan ini diisi oleh pakar yang berkompeten dalam bidangnya. 


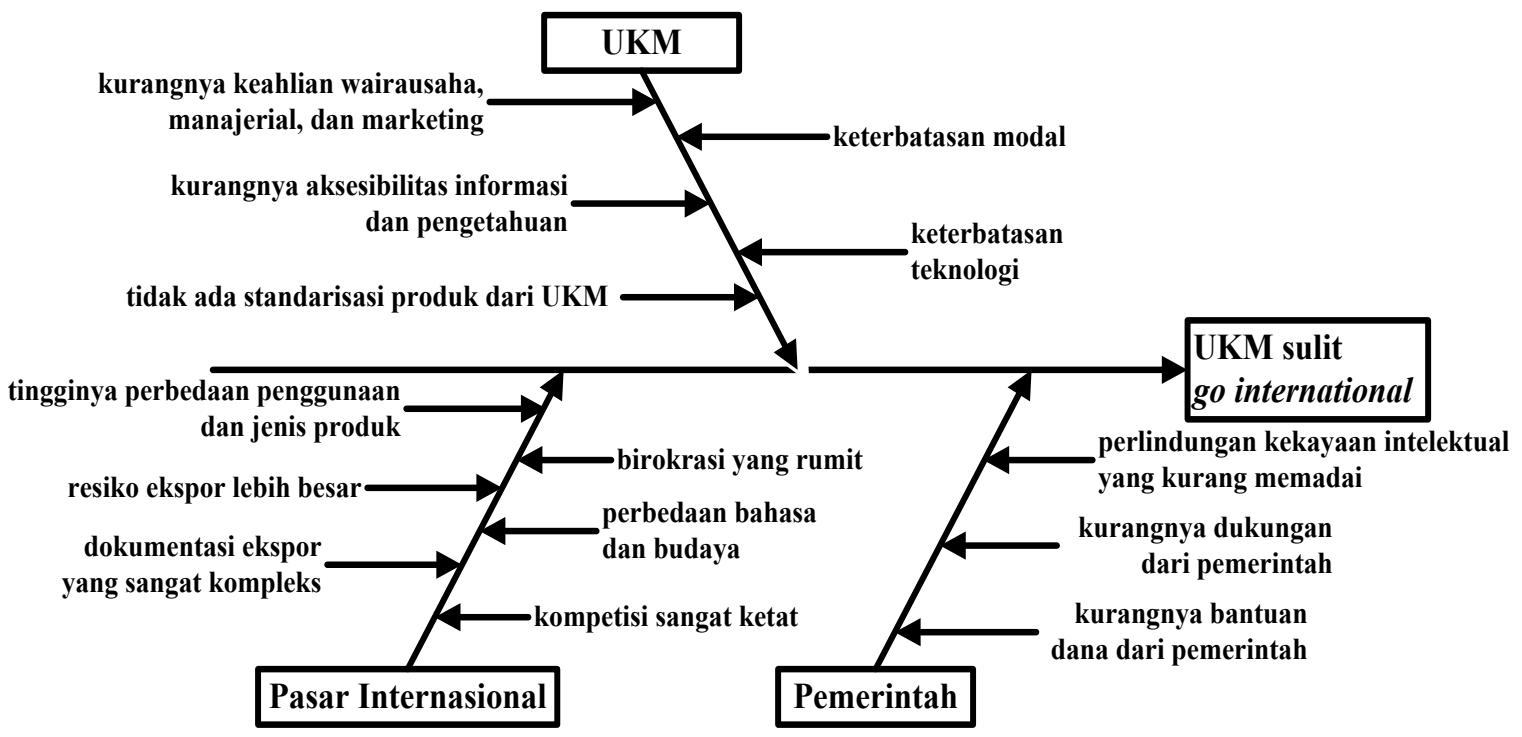

Gambar 2. Cause and Effect Diagram Kendala Internasionalisasi UKM

\subsection{Langkah Implementasi}

Langkah implementasi pengelolaan Integrated Woodencraft Cluster dijelaskan berdasarkan cakupan ketiga sistem dan prinsip yang diaplikasikan di dalamnya, yaitu sistem distribusi berbasis SCM, sistem informasi berbasis website dan marketplace, dan prinsip JIT.

\subsubsection{Sistem Distribusi Berbasis Supply Chain Management}

$\begin{array}{ccc}\text { Penerapan } & \text { SCM dalam Integrated } \\ \text { Woodencraft } & \text { Cluster bertujuan untuk }\end{array}$ mengelola pendistribusian barang, uang, dan informasi mulai dari pihak pemasok bahan baku sampai bagian penjualan, sehingga aliran ketiga komponen tersebut dapat berlangsung dengan benar dan tepat. Khusus untuk barang produksi,dalam hal ini adalah kerajinan kayu, penerapan SCM ini akan memberikan informasi yang tepat sehingga barang akan diproduksi dan didistribusikan dalam jumlah dan waktu yang tepat. Secara umum, sistem distribusi barang pada Integrated Woodencraft Cluster dapat dilihat pada Gambar 4.

Berdasarkan gambar 4, Integrated Woodencraft Cluster terdiri dari empat lini utama yang menjadi komponen penting di dalam klaster, yaitu Lini Supplier, Lini Produksi (UKM), Lini Penjualan, dan Lini Informasi. Tiga lini yang pertama saling berinteraksi secara langsung dengan aliran barang yang produksi.

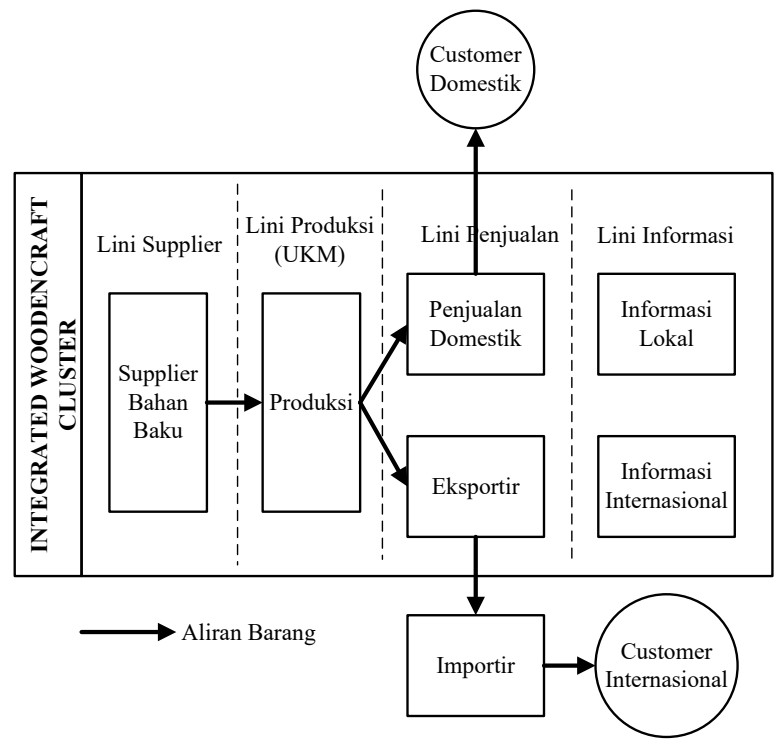

Gambar 4. Distribusi Barang dengan Penerapan SCM pada Integrated Woodencraft Cluster

\subsubsection{Lini Supplier}

Lini Supplier merupakan lini pertama yang menjadi dasar dalam implementasi Integrated Woodencraft Cluster. Pada sistem konvensional, pihak pemasok bahan baku hanya berinteraksi dengan bagian produksi (UKM), dan tidak terikat dengan hal lain di luar penyediaan bahan baku. Namun, dalam Integrated Woodencraft Cluster, para pemasok bahan baku kerajinan kayu direkrut untuk bergabung menjadi sebuah kesatuan di dalam klaster. 
Perekrutan pemasok bahan baku tersebut dapat menguntungkan kedua belah pihak. Dari pihak supplier, mereka akan mendapatkan pelanggan tetap yang akan selalu memesan bahan baku kerajinan kayu yang mereka sediakan. Dengan adanya pelanggan yang sudah pasti, para pemasok tidak perlu mencari pelanggan lain yang pesanannya tidak menentu.

Dari pihak klaster, lini produksi, dalam hal ini adalah para pelaku UKM, akan mendapatkan bahan baku dengan kualitas yang terjamin serta dengan harga yang relatif lebih murah, karena pemesanan bahan baku dilakukan dalam jumlah besar untuk semua UKM yang tergabung dalam klaster.

\subsubsection{Lini Produksi}

Lini produksi merupakan lini ke dua dalam Integrated Woodencraft Cluster. Lini ini memegang peranan yang paling penting. Lini produksi terdiri atas berbagai sentra yang tergabung dalam klaster. Masing-masing sentra memiliki ciri khas tersendiri berdasarkan jenis kerajinan kayu yang diproduksinya. Masingmasing sentra terdiri dari beberapa UKM, yang hasil produksinya mengacu pada sentra yang bersangkutan.

Gambar 5 menunjukkan aliran barang dari lini supplier ke lini produksi serta komponen dari lini produksi.

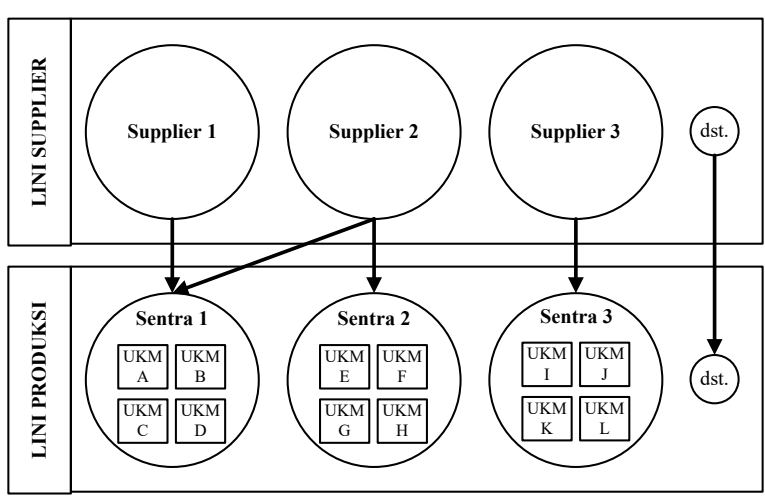

Gambar 5. Aliran Bahan Baku dari Lini Supplier ke Lini Produksi serta Komponen Penyusun Lini Produksi

Dari gambar 5 dapat dilihat bahwa masingmasing sentra UKM telah memiliki pemasok bahan baku sendiri yang tentu saja sudah bergabung dalam klaster. Masing-masing sentra memilih pemasok yang sesuai dengan kerajinan kayu yang diproduksinya. Misalnya: sentra kerajinan ukiran kayu menjalin kerja sama dengan pemasok kayu yang cocok untuk ukiran. Dalam kerja sama tersebut, tidak menutup kemungkinan satu pemasok bekerja sama dengan lebih dari satu sentra atau satu sentra bekerja sama dengan lebih dari satu pemasok, dengan catatan bahwa kerja sama tersebut masih dalam ruang lingkup klaster.

\subsubsection{Lini Penjualan}

Lini penjualan berfungsi untuk memasarkan atau menjual produk akhir kerajinan kayu. Lini penjualan dibagi menjadi dua berdasarkan jangkauan pemasarannya, yaitu penjualan domestik serta penjualan internasional (eksportir).

Penjualan domestik hanya bisa memenuhi pelanggan domestik atau pelanggan dalam negeri saja. tempat penjualannya dapat berupa kios, toko, atau semacam pasar dan swalayan yang khusus berisi kerajinan kayu. Penjualan kerajinan kayu berskala domestik dapat dilakukan sendiri oleh pemilik UKM atau dapat dialihkan ke pihak lain yang khusus menangani penjualan.

Sementara itu, penjualan internasional mencakup para pelanggan di luar negeri. Dalam hal ini, Integrated Woodencraft Cluster membentuk sebuah badan eksportir di dalam klaster yang khusus mengurus masalah ekspor kerajinan kayu ke luar negeri. Eksportir tersebut mengurusi masalah administrasi, pemesanan, transportasi, pajak, dan hal-hal lain yang berhubungan dengan ekspor. Para tenaga kerja yang mengurusi masalah ekspor diambil dari orang-orang yang telah memiliki background tentang ekspor dan akan diberikan pelatihan, sehingga ketika Integrated Woodencraft Cluster mempekerjakan mereka, kemampuan dan kesiapan mereka tidak perlu diragukan lagi. Eksportir tersebut yang akan berhubungan langsung dengan importir dari luar negeri.

Keuntungan dari pembentukan badan ekspor yang mandiri ini adalah untuk lebih menjamin kepercayaan penjualan kerajinan kayu ke luar negeri. Badan eksportir tersebut dapat dikontrol oleh klaster. Selain itu, pembentukan badan ekspor mandiri membutuhkan biaya yang lebih murah jika dibandingkan menjalin kerja sama dengan pihak eksportir luar.

\subsubsection{Lini Informasi}

Lini ke empat tersebut mengatur semua aliran informasi yang masuk ke dalam klaster 
maupun yang keluar dari klaster. Setiap informasi yang keluar masuk klaster, sekecil apapun itu, harus melewati atau disampaikan ke bagian lini informasi. Penjelasan terperinci dari lini informasi akan dijelaskan pada bagian selanjutnya.

Penerapan SCM dalam Integrated Woodencraft Cluster antara lain akan mengurangi bullwhip effect yaitu osilasi amplitudo demand yang semakin membesar akibat ketidakvalidan informasi atau kecenderungan perilaku pelaku SCM pada setiap bagian yang memberikan safety stock. Pengurangan rantai pasok pada eksportir dan penerapan sistem klaster akan mengurangi tingginya osilasi amplitudo demand tersebut karena hanya terdapat tiga tahap dalam sistem ini yaitu customer, importir, dan klaster.

\subsubsection{Sistem Informasi Berbasis Website dan Marketplace}

Sistem informasi sangat penting untuk menunjang perkembangan sebuah usaha, tidak terkecuali bagi UKM-UKM yang tergabung dalam Integrated Woodencraft Cluster. Seperti yang disebutkan oleh Aziz (2007), UKM sudah waktunya memikirkan bagaimana untuk mengatur dan mengelola informasi yang sesuai dengan misi, visi, dan kekhasan manajemen.

Berdasarkan studi yang telah dilakukan oleh Wahid dan Iswari (2007), dari 51 UKM di Yogyakarta, hanya sebanyak $43,1 \%$ yang sudah menerapkan sistem informasi berbasis website. Hal tersebut menunjukkan bahwa penggunaan website di kalangan para pelaku UKM belum begitu populer. Dengan adanya tantangan tersebut, Integrated Woodencraft Cluster berusaha untuk mengaplikasikan sistem informasi berbasis website.

Seperti yang sudah diuraikan sebelumnya, Integrated Woodencraft Cluster mempunyai sebuah Lini Informasi yang mengatur semua aliran informasi yang masuk ke dalam klaster maupun yang keluar dari klaster. Informasi yang masuk ke dalam klaster akan langsung disampaikan ke lini yang bersangkutan, sehingga perolehan informasi akan berlangsung dengan cepat. Hal tersebut akan mengurangi kesalahan dalam melakukan proses pemesanan, produksi, distribusi, dan penjualan.

Menurut penelitian Wahid dan Iswari (2007) terhadap 51 sampel UKM di DIY, aktivitas online yang dilakukan oleh UKM ditunjukkan pada Tabel 3. Integrated Woodencraft Cluster berusaha melakukan semua aktivitas yang tercakup dalam Tabel 3 secara online atau berbasis website. Implementasi tersebut pada akhirnya akan meningkatkan produktivitas dan keuntungan klaster. Selain itu, Integrated Woodencraft Cluster juga akan menjadi klaster yang terdepan dalam pemanfaatan sistem informasi berbasis website.

Tabel 3. Aktivitas Online yang Dilakukan UKM

\begin{tabular}{clc}
\hline No & \multicolumn{1}{c}{ Penggunaan } & \% UKM \\
\hline 1 & Mencari informasi pasar & 48,9 \\
2 & Mencari informasi desain & 42,7 \\
3 & Memasarkan produk & 32,3 \\
4 & Komunikasi dengan & 31,2 \\
& $\begin{array}{l}\text { partner/mitra } \\
5\end{array}$ & Komunikasi dengan \\
& $\begin{array}{l}\text { konsumen } \\
6\end{array}$ & Menfasilitasi pemesanan \\
& $\begin{array}{l}\text { online } \\
7\end{array}$ & Komunikasi dengan \\
& $\begin{array}{l}\text { suplier/pemasok } \\
8\end{array}$ & 19,8 \\
\hline
\end{tabular}

Aktivitas online yang termasuk paling penting dalam Integrated Woodencraft Cluster adalah pemasaran produk kepada para pelanggan dan memfasilitasi pemesanan online. Aliran informasi kedua aktivitas tersebut ditunjukkan pada Gambar 6 .

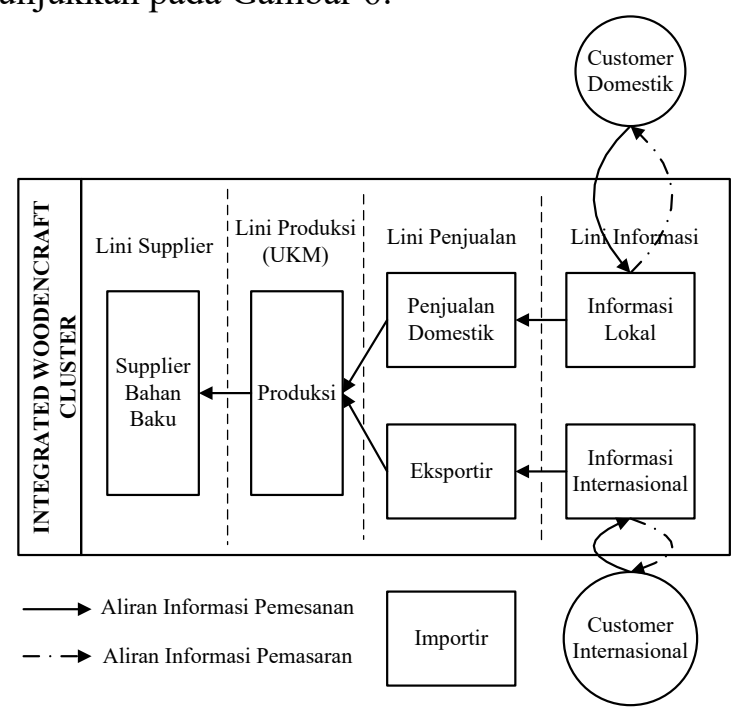

Gambar 6. Aliran Informasi Pemesanan dan Pemasaran Produk Integrated Woodencraft Cluster

\subsubsection{Prinsip Just In Time}

Prinsip Just In Time yang diterapkan adalah pemerataan beban produksi di setiap unit kerja sesuai dengan kuantitas permintaan. Pada produksi kerajinan kayu, terdapat 2 macam produk yaitu produk assembly dan nonassembly. Produk assembly dapat dikerjakan dengan tipe produksi paralel. Sedangkan 
nonassembly menggunakan tipe produksi seri. Gambar 7 dan Gambar 8 merupakan contoh produk assembly dan non-assembly.

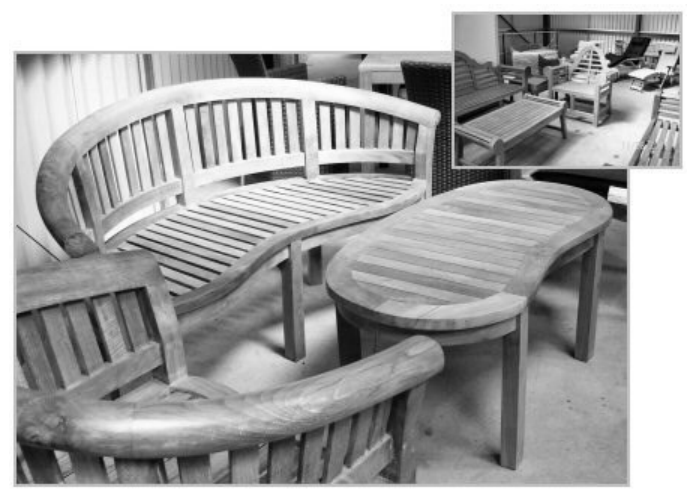

Gambar 7. Produk Assembly Kursi Meja Kayu Ukir

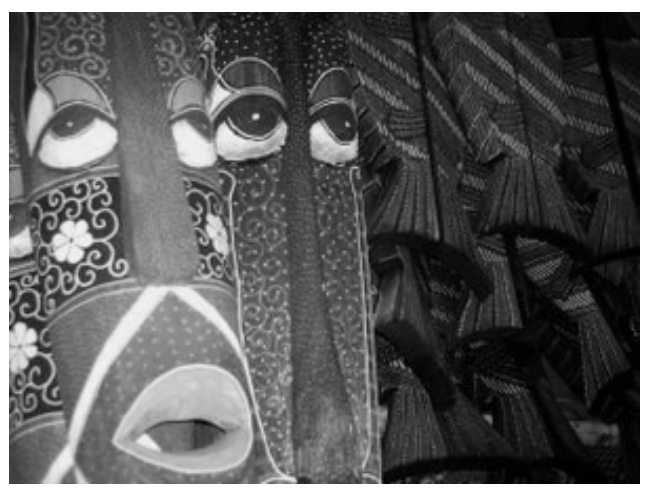

Gambar 8. Produk Non-Assembly Batik Kayu

Tipe paralel pada produk assembly dilakukan dengan menggerakkan seluruh unit kerja bersama sesuai dengan kuantitas yang diminta, sehingga proses assembly dapat langsung dilakukan tanpa penundaan sesuai dengan kuantitas yang diminta. Sedangkan tipe seri seluruh proses penyelesaian satu produk dilakukan oleh satu unit kerja. Hanya saja, JIT diterapkan dalam pemerataan beban produksi. Contoh alur produksi assembly dan nonassembly dengan jumlah permintaan 60 unit kursi-meja ukir dan 60 unit batik kayu ditunjukkan pada Gambar 9.

Sistem di atas akan mengurangi penumpukan bahan baku karena akan disebarkan pada unit kerja. Selain itu, pada titik akhir sentra finishing akan langsung menerima 60 paket sekaligus yang dapat diassembly sehingga waktu lebih singkat. Jika sistem ini dikerjakan secara seri maka akan membuat waktu produksi semakin lama. Sedangkan untuk produk non-assembly tidak dapat dikerjakan dengan sistem paralel, contohnya batik kayu/ patung kayu. Sistem seri yang diterapkan menitikberatkan pada pembagian kuantitas permintaan. Misalnya ada 60 unit permintaan. Dan ada 6 unit kerja dengan pembagian stasiun kerja sebanyak 2 unit. Maka setiap unit kerja mengerjakan proses pahat sebanyak 30 unit permintaan. Kemudian, setelah proses pahat selesai, baru akan masuk pada proses finishing seperti pengampelasan dan pengecatan.

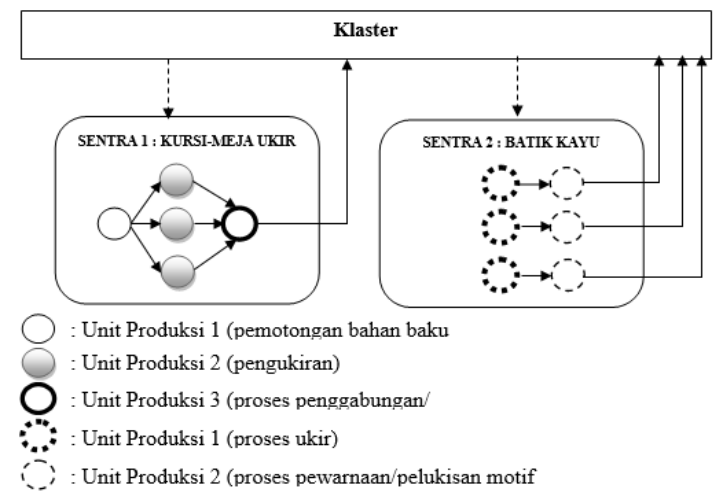

Gambar 9. Contoh Alur Produksi Sentra KursiMeja Ukir dan Batik Kayu

\subsection{Keunggulan Program}

Keunggulan Integrated Woodencraft Cluster jika dibandingkan dengan sistem klaster konvensional adalah (1) Mempunyai visi yang pasti, yaitu meningkatkan penetrasi produk kerajinan kayu ke pasar internasional tanpa mengabaikan pasar domestik; (2) Mempunyai sistem manajerial yang lebih berkompeten dan terstruktur; (3) Mempunyai badan ekspor mandiri yang fokus mengelola penjualan produk dari dalam klaster; (4) Mempunyai pemasok bahan baku yang telah teruji kualitasnya; (5) Mempunyai lini informasi yang dikendalikan langsung oleh ahli teknologi informasi, sehingga semua informasi yang masuk maupun keluar klaster dapat dialirkan tepat waktu dan tepat sasaran;

Semua UKM, baik UKM yang berskala menengah maupun yang berskala kecil, dapat berpartisipasi dalam kancah perdagangan internasional dengan menyediakan produk kerajinan kayu mereka di dalam klaster.

\section{KESIMPULAN}

Program Integrated Woodencraft Cluster dirancang untuk membantu UKM kerajinan kayu mengangkat produk mereka ke kancah internasional. Program tersebut tidak hanya memfasilitasi UKM skala menengah, tetapi 
juga mewadahi UKM skala kecil atau skala rumah tangga. Integrated Woodencraft Cluster melakukan ekspansi pemasaran produk tidak hanya dalam cakupan wilayah domestik saja, tetapi juga mengutamakan pasar internasional.

Langkah yang dilakukan Integrated Woodencraft Cluster dalam rangka internasionalisasi UKM kerajinan kayu adalah dengan mengintegrasikan tiga hal, yaitu sistem distribusi berbasis SCM dengan empat lini (lini supplier, produksi, penjualan, dan informasi), sistem informasi berbasis website, serta penerapan prinsip JIT. Selain itu, Integrated Woodencraft Cluster juga merekrut dan menjalin kerja sama dengan pihak-pihak yang berkaitan dengan tujuan ekspornya.

Manfaat dari Integrated Woodencraft Cluster akan dirasakan terutama oleh para pelaku UKM. Keuntungan dari hasil penjualan produk mereka akan meningkat sebagai akibat dari ekspansi pemasaran ke luar negeri. Selain itu masyarakat di sekitar sentra UKM juga akan mendapat manfaat dengan terserapnya tenaga kerja oleh UKM. Dengan kata lain, Integrated Woodencraft Cluster pada akhirnya akan meningkatkan kesejahteraan masyarakat dan negara.

\section{DAFTAR PUSTAKA}

Aziz, Noor. (2007). Penerapan Sistem Informasi Pemasaran pada Usaha Kecil Menengah (UKM) di Kota Malang, Usul Penelitian Universitas Muhammadiyah Malang, Malang.

Disperindagkom DIY. (2009). Daftar Sentra Industri Kecil dan Menengah. Disperindagkom, Yogyakarta

Disperindagkom DIY. (2011). Kinerja Ekspor dan Impor Provinsi Daerah Istimewa Yogyakarta. Yogyakarta

Disperindagkom,

Foghani, S., Mahadi, B., Omar, R., 2017, Promoting Clusters and Networks for Small and Medium Enterprises to Economic Development in the Globalization https://doi.org/10.1177/215824401769 7152

Global Facilitation Partnership. (2005). Enabling SMEs to Enter The International Supply Chain, The World Bank Group, GFP Explanatory Notes.

Marijan, K. (2005). Mengembangkan Industri Kecil Menengah melalui Pendekatan Klaster. Insan. Vol. 7 No. 3.

Mukaffi, Z. (2010). Distribusi Spasial UKM di Masa Krisis Ekonomi. (diakses online 2 Februari 2011). URL: http://www.zaimmukaffi.com/ekonomi /78-distribusi-spasial-ukm-di-masakrisis-ekonomi.pdf

Sari, Ni Nengah Maya Permata dan Yasa, Ni Nyoman Kerti Yasa. (2016). Peran Keunggulan Kompetitif Memediasi Orientasi Padar dengan Internasionalisasi UKM Mebel di Kabupaten Badung. E-Journal Ekonomi dan Bisnis Universitas Udayana, 5, p. 1651-1678

Wahid, Fathul dan Iswari, Lizda. (2007). Adopsi Teknologi Informasi oleh Usaha Kecil dan Menengah di Indonesia. Seminar Nasional Aplikasi Teknologi Informasi 2007 (SNATI 2007), ISSN: 1907-5022

Wahyudi, Muhammad. (2009). Analisis Faktorfaktor yang Mempengaruhi Penggunaan Informasi Akuntansi pada Usaha Kecil dan Menengah (UKM) di Yogyakarta. Master Thesis. Universitas Diponegoro, Semarang.

Winarto, L. dan Nazir, D. (2006). Pengkajian Produk Unggulan dalam Meningkatkan Ekspor UKM dan Pengembangan Ekonomi Lokal. Jurnal Pengkajian Koperasi dan UKM, Nomor 1 Tahun I.

Zen, Muhammad. (2009). UKM, Banyak Kelemahan Tapi Tahan Banting, diakses online 21 Februari 2011, URL: http://mhzen.wordpress.com/2009/07/ 11/ukm-banyak-kelemahan-tapi-tahanbanting/ 